\title{
ENERGY AND COMMUNICATION REQUIREMENTS FOR NETWORK OF E-BAND RADARS AS SENSORS
}

\author{
Marko Pajić ${ }^{1,2, *}$, \\ Bojan Džolić ${ }^{1,2}$, \\ Miroslav Perić2 \\ Mladen Veinovic
}

'Singidunum University,

Belgrade, Serbia

2Vlatacom Institute,

Belgrade, Serbia
Correspondence:

Marko Pajić

e-mail:

marko.pajic@vlatacom.com

\begin{abstract}
:
E-band radars EBR are very promising short distance high-resolution sensors for safety and smart city solutions. In order to achieve larger scale coverage, we have investigated possibility of gaining raw signal from multiple EBRs for purpose of centralized data processing and fusion. Based on publicly available data about EBR ranges, resolution and data formats, we have considered requirements for implementation of communication and power network for them. We have presented data for both static and dynamic scenario. In static scenario EBR positions are fixed, while in dynamic scenario some of EBRs are located on vehicles with known position obtained by GPS.
\end{abstract}

Keywords:

radar, smart city, communication, energy efficiency.

\section{INTRODUCTION}

For traffic monitoring in smart city usually a set of cameras are used [1]. In typical installation camera transmits compressed video image over internet protocol - IP based network [2] to control center where video storage is performed [3]. IP traffic throughput generated by single camera depends on its resolution, frame rate and used compression. The analysis of required IP communication bandwidth is given in [4] we can assume values from about $1 \mathrm{Mbps}$ to $10 \mathrm{Mbps}$ per camera, which yields to huge requirements in both communication bandwidth - $\mathrm{CBF}$ and storage capacity - SC.

In order to reduce $\mathrm{CBF}$ and $\mathrm{SC}$, in modern surveillance systems only significant events are transmitted in full image quality and stored if needed, while insignificant video is recorded in lower quality. The decision about significance is obtained either by operator or video analytic subsystem [5]. Usage of smart sensor technologies for vehicle and human detection [6] could be additionally exploited for more accurate detection of significant events. The main drawback of its usage in larger scale is their low resolution, installation problems and necessity of communication with control center or cameras themselves. In this paper we analyze possibility to replace these sensors by E-band radars - EBR [7] as a vehicle [8], pedestrian [9] and other events sensors with higher resolution and range compared to conventional smart sensors. Similar approach for lower bands is given in [10]. 
EBR operates in frequency range from 76 to $81 \mathrm{GHz}$ and its usage is regulated by ITU-R recommendations M.2057 [11] and M.1452 [12]. These recommendations define radio parameters that minimize possibility of interference with other system and also give indication about expected performance.

Thanks to EBR main application as driving assistance sensors, there are commercially available low-cost solutions [13] which justify technical feasibility of this approach. Besides this new application, EBRs are traditionally used for airport security applications [14][15] [16].

The paper is structured as follows. In section II we describe main EBR operation theory and define basic parameters. In chapter III we analyze one typical urban use case with static radars. In chapter IV we analyze cooperative vehicle radars scenario and finally in chapter $\mathrm{V}$ we gave the conclusions.

\section{E-BAND RADAR BASIC OPERATION}

Block diagram of one frequency-modulated continuous wave (FMCW) radar system is shown in Figure 1. Basic operating principles of FMCW radar are:

- A local oscillator (LO) generates a chirp, linear frequency-modulated continuous wave signal.

- The chirp is amplified by the PA and transmitted by a transmit antenna.

- Receive antenna receives any reflection of the chirp.

- LNA amplifies the received signal.

- Mixer combines received and LO signal to produce intermediate (or beat) frequency (IF) signal.

- This signal is subsequently digitalized in ADC and processed in DSP.

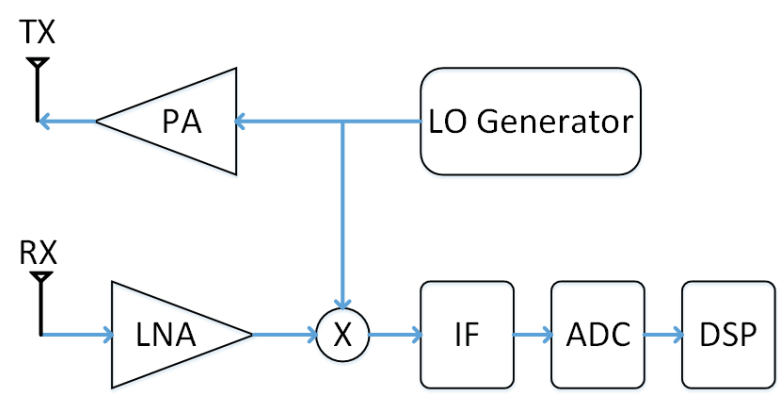

Fig. 1. FMCW radar block diagram
Chirp is a tone whose frequency is linearly increased with time. Figure 2 shows typical FMCW chirp pattern, with frequency as a function of time. The chirp is characterized by bandwidth (B) and sweep time $\left(\mathrm{T}_{\mathrm{s}}\right)$.

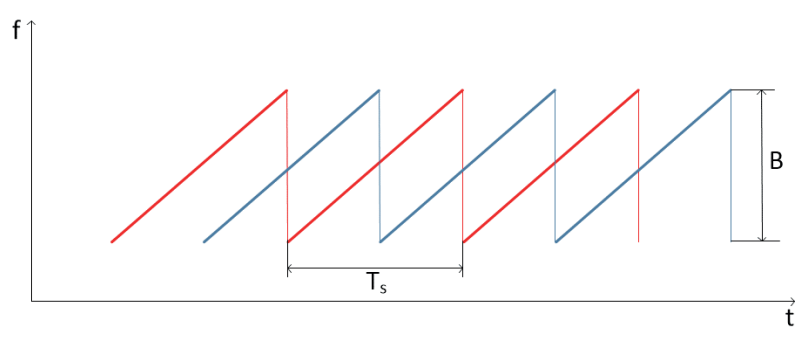

Fig. 2. Typical FMCW chirp pattern

FMCW radar can successfully measure range, angle and velocity of the target. This paper will focus on range and angle of arrival of the target.

\section{Maximum range}

Maximum range of a radar is directly related either to supported IF bandwidth or to signal to noise ratio (SNR) of received signal.

Maximum range related to supported IF bandwidth is given in Equation 1:

Range $_{\max }=\frac{\mathbf{F}_{\text {max }} c}{2 S}$

$\mathrm{IF}_{\text {max }}$ - Maximum supported IF bandwidth

c - Speed of light

$\mathrm{S}-$ Chirp slope $\left(\mathrm{S}=\mathrm{B} / \mathrm{T}_{\mathrm{S}}\right)$

From the previous equation, it is clear that maximum range is depending on chirp characteristics and supported IF bandwidth which is on the other hand dependent on ADC requirements, specifically ADC sampling frequency and sampling mode.

Maximum range related to SNR of received signal is derived from radar equation [17] and it is depending on radar's RF performance (transmit power, receiver sensitivity, antenna gains, chirp characteristics) and target characteristics (Radar Cross Section - RCS):

$$
\text { Range }_{\max (S N R)}=\sqrt[4]{\frac{P_{T} G_{R X} G_{T X} c^{2} \sigma N T_{S}}{f_{c}^{2}(4 \pi) k T_{\operatorname{det}} N_{F} S N R_{\operatorname{det}}}}
$$


$\mathrm{P}_{\mathrm{T}}$ - Transmit power

$\mathrm{G}_{\mathrm{RX}}, \mathrm{G}_{\mathrm{TX}}$ - Antenna gain (receiver and transmitter)

$\mathrm{c}$ - Speed of light

$\sigma$ - Target Radar Cross Section - RCS

$\mathrm{N}$ - Number of chirps

$\mathrm{T}_{\mathrm{S}}-$ Chirp time

K - Boltzman constant

$\mathrm{T}_{\text {det }}$ - Temperature

$\mathrm{N}_{\mathrm{F}}$ - Noise figure

$\mathrm{SNR}_{\text {det }}-$ Minimum required SNR

For range calculation based on signal to noise ratio we have assumed values for radar cross-section reported in [8] as $+12 \mathrm{dBsm}$ for vehicle and $-10 \mathrm{dBsm}$ for pedestrian.

\section{Range resolution}

Important parameter of FMCW radar is range resolution. This defines the minimum distance between two targets that allows the radar to detect them as separate objects. Range resolution is calculated from the following equation:

$$
\text { Range }_{\text {res }}=\frac{c}{2 B}
$$

C - Speed of light

\section{B - Chirp bandwidth}

Range resolution is directly dependent of chirp bandwidth, the larger the chirp bandwidth, the better the range resolution. For E-band radars that operate in frequency range of 76 to $81 \mathrm{GHz}$, approximate range resolution is $4 \mathrm{~cm}$.

\section{Angular range}

In order to exactly determine the position of the target in front of the radar, apart from its range, the exact angle of arrival of the target needs to be known. To estimate the angle of arrival, radar is using multiple receivers. Figure 3 is showing the basics of radar's angle estimation.

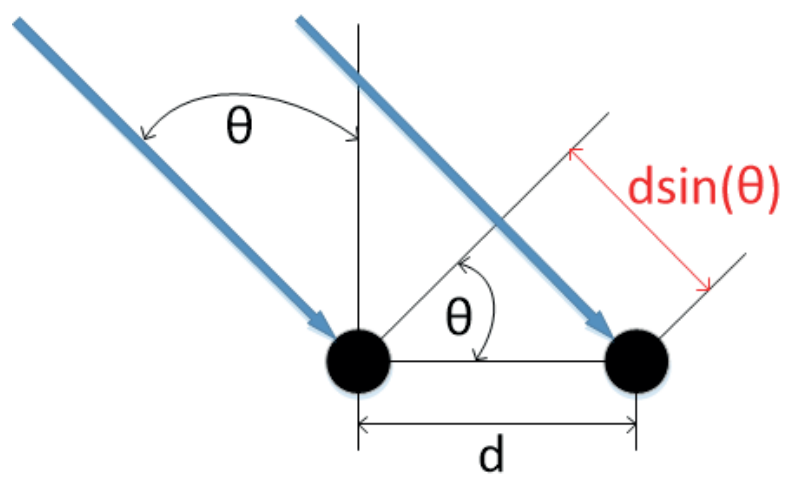

Fig. 3. Angle estimation

Maximum angular range or radar field of view is depending on the distance between receiver antennas and wavelength:

$\theta_{\max }=\sin ^{-1}\left(\frac{\lambda}{2 d}\right)$

$\lambda$ - Wavelength

$\mathrm{d}$ - Distance between two receiver antennas

Maximum angular range is $\pm 90^{\circ}$ for spacing between two antennas of $\lambda / 2$.

\section{Angular resolution}

While range resolution defines the minimum distance between two targets, angular resolution defines minimum angle of arrival of two targets that allows the radar to detect them as separate objects. Angular resolution is directly related to the number of transmit and receive antennas, meaning the larger the number of antennas, the better the resolution. Angular resolution is described by the following equation:

$\theta_{r e s}=\frac{\lambda}{d N_{R X} N_{T X} \cos \theta} \frac{180}{\pi}$

$\lambda$ - Wavelength

$\theta$ - Angle of arrival

$\mathrm{N}_{\mathrm{RX}}$ - Number of receiver antennas

$\mathrm{N}_{\mathrm{TX}}$ - Number of transmitter antennas 


\section{Radar parameters examples}

Based on publicly available data about EBR ranges, resolution and data formats, we have presented Table I as a comparison of performances of some radars.

Table 1. E-band Radar parameters

\begin{tabular}{|c|c|c|c|}
\hline & Radar 1 & Radar 2 & Radar 2 \\
\hline Company & ELVA-1 & \multicolumn{2}{|c|}{ TI AVR 1243} \\
\hline Radar type & $\begin{array}{l}\text { Fault object } \\
\text { detection } \\
\text { (FOD) }\end{array}$ & \multicolumn{2}{|c|}{ Automotive } \\
\hline $\begin{array}{l}\text { Central } \\
\text { frequency }\end{array}$ & $76 \mathrm{GHz}$ & \multicolumn{2}{|c|}{$76 \mathrm{GHz}$} \\
\hline $\begin{array}{l}\text { Modulation } \\
\text { type }\end{array}$ & FMCW & \multicolumn{2}{|c|}{ FMCW } \\
\hline Bandwidth & $500 \mathrm{MHz}$ & $300 \mathrm{MHz}$ & $540 \mathrm{MHz}$ \\
\hline Sweep time & $1-10 \mathrm{~ms}$ & 30 us & 50 us \\
\hline Ramp slope & $<0.5 \mathrm{MHz} / \mathrm{us}$ & 10 & 12 \\
\hline $\begin{array}{l}\text { Samples per } \\
\text { chirp }\end{array}$ & 8192 & 500 & 500 \\
\hline Resolution & 14 bits & \multicolumn{2}{|c|}{12 bits, complex IQ } \\
\hline $\begin{array}{l}\text { Transmitter } \\
\text { power }\end{array}$ & $24.8 \mathrm{dBm}$ & \multicolumn{2}{|c|}{$12 \mathrm{dBm}$} \\
\hline $\begin{array}{l}\text { Antenna } \\
\text { type }\end{array}$ & $\begin{array}{l}\text { Parabolic } \\
\text { on pan-tilt } \\
\text { platform }\end{array}$ & \multicolumn{2}{|c|}{$\begin{array}{l}\text { Printed frequency } \\
\text { scanning }\end{array}$} \\
\hline Antenna gain & $50 \mathrm{~dB}$ & \multicolumn{2}{|c|}{$10.5 \mathrm{dBi}$} \\
\hline $\begin{array}{l}\text { Antenna } \\
\text { beam width }\end{array}$ & $0.4 \mathrm{deg}$ & \multicolumn{2}{|c|}{$30 \mathrm{deg}$} \\
\hline EIRP & $74.8 \mathrm{dBi}$ & \multicolumn{2}{|c|}{$24 \mathrm{dBi}$} \\
\hline Noise figure & n.a. & \multicolumn{2}{|c|}{$14 \mathrm{~dB}$} \\
\hline $\begin{array}{l}\text { Range } \\
\text { (vehicle) }\end{array}$ & n.a. & $150 \mathrm{~m}$ & $70 \mathrm{~m}$ \\
\hline $\begin{array}{l}\text { Range } \\
\text { (pedestrian) }\end{array}$ & n.a. & $80 \mathrm{~m}$ & $40 \mathrm{~m}$ \\
\hline $\begin{array}{l}\text { Range } \\
\text { (other object) }\end{array}$ & $1000 \mathrm{~m}^{\star}$ & $225 \mathrm{~m}$ & $125 \mathrm{~m}$ \\
\hline $\begin{array}{l}\text { Azimuth } \\
\text { angular } \\
\text { resolution }\end{array}$ & $0.4 \mathrm{deg}$ & $1 \mathrm{deg}$ & $1 \mathrm{deg}$ \\
\hline $\begin{array}{l}\text { Range } \\
\text { resolution }\end{array}$ & $0.3 \mathrm{~m}$ & $0.5 \mathrm{~m}$ & $0.28 \mathrm{~m}$ \\
\hline $\begin{array}{l}\text { Pan-tilt } \\
\text { speed }\end{array}$ & $0.1 \mathrm{deg}$ & n.a. & n.a. \\
\hline
\end{tabular}

\begin{tabular}{lccc}
\hline $\begin{array}{l}\text { Raw image } \\
\text { throughput }\end{array}$ & $15-131 \mathrm{Mbps}$ & $\begin{array}{c}150-600 \\
\text { Mbps }\end{array}$ & $\begin{array}{c}150-600 \\
\text { Mbps }\end{array}$ \\
\hline $\begin{array}{l}\text { Power } \\
\text { consumption } \\
\text { estimation }\end{array}$ & $500 \mathrm{~W}^{*}$ & $2 \mathrm{~W}$ radar front end \\
& & $15 \mathrm{~W}$ signal processing \\
\hline
\end{tabular}

${ }^{*}$ Manufacturer data

For further calculations we would assume values for radar 2 with chirp parameters set up to successfully detect vehicles at the distance of 150 meters.

\section{URBAN USE CASE}

We have analyzed typical urban use case of static radar installation along a busy two directional city street.

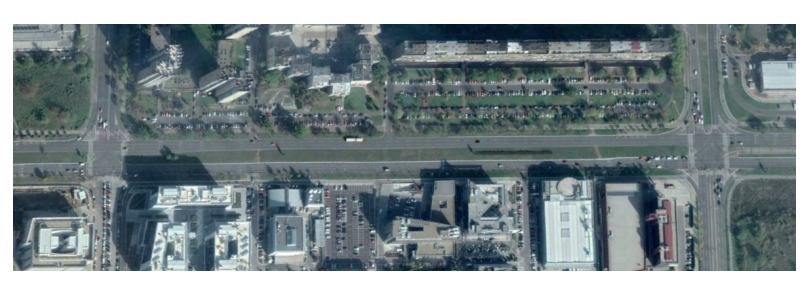

Fig. 4. Urban use case map view

We have found that to cover this area we need to position the radars at approximate distance of 100-150 meters. Since these radars are small in size, existing utility poles used for city lighting can be used as installation points. Figure 5 depicts idealistic case of radar network layout, taking into account the parameters from Table I in regards to vehicle range measurements and antennas beam width. The radars are placed alternately on both sides of the street in a way that two adjacent radars on the same side of the street are at the maximum distance of 200 meters.

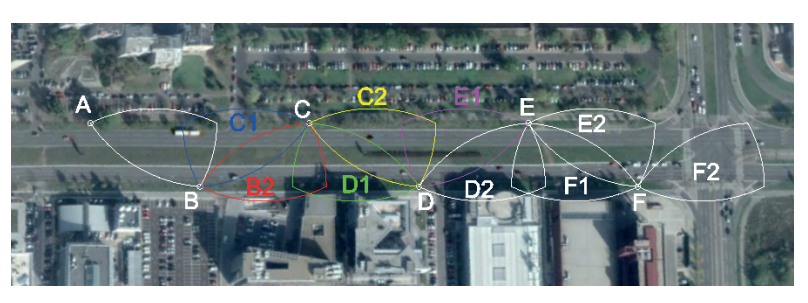

Fig. 5. Urban use case system topology 
Figure 6 illustrates coverage zones of radars installed in radar nodes $\mathrm{B}, \mathrm{C}$ and $\mathrm{D}$. It is clear that the coverage zone of radar B2, marked red in the Figure 6, is overlapping with coverage zones of radars $\mathrm{C} 1$ (blue) and D1 (green).

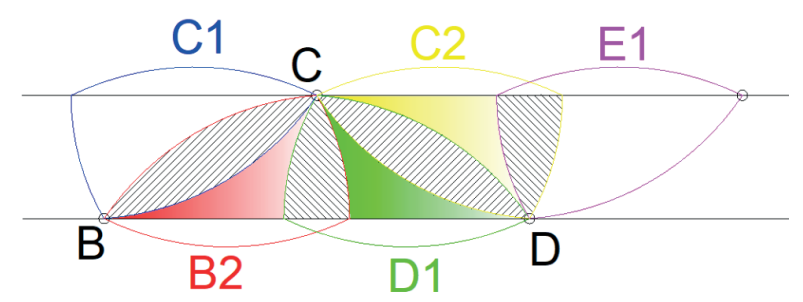

Fig. 6. Overlapping radar coverage zones

Raw data taken from radars with overlapping radar zones is processed in control nodes. Control nodes are collocated with the radars and installed on the same utility poles. Signals from control nodes are then transferred further to the Command and Control Center (C2 Center). Block diagram of signal flow from the radar to C2 Center is shown in Figure 7 on the following page.

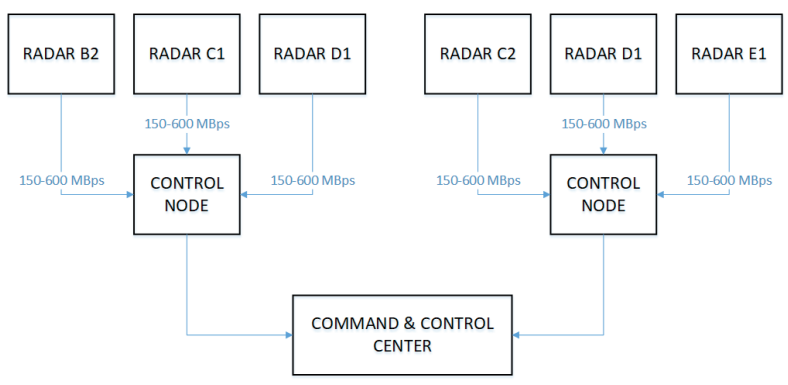

Fig. 7. Signal flow from radar to C2 Center

Taking into account that raw image throughput from radar to control node is $150-600 \mathrm{Mbps}$, communication requirements are very strict. Communication network that can sustain such capacity and is suitable for infrastructure installation between utility poles is either fiberoptic network or visible light communication network.

In terms of energy requirements, since power consumption of each radar is $17 \mathrm{~W}$ and it is intended to be installed on utility pole used for city lighting, needed power requirements can be obtained from city grid. Alternatively, as a backup and in case city grid is unavailable, small solar panels installed also on top of utility poles can be used.

\section{COOPERATIVE VEHICLES SCENARIO}

In previous chapter we have analyzed static scenario where EBR positions are fixed. In this chapter we will focus on dynamic scenario where additional data is being obtained from cooperative vehicles equipped with EBR radars.

General network concept remains the same in terms of control nodes that gather, process and transfer the information to $\mathrm{C} 2$ center (Figure 8).

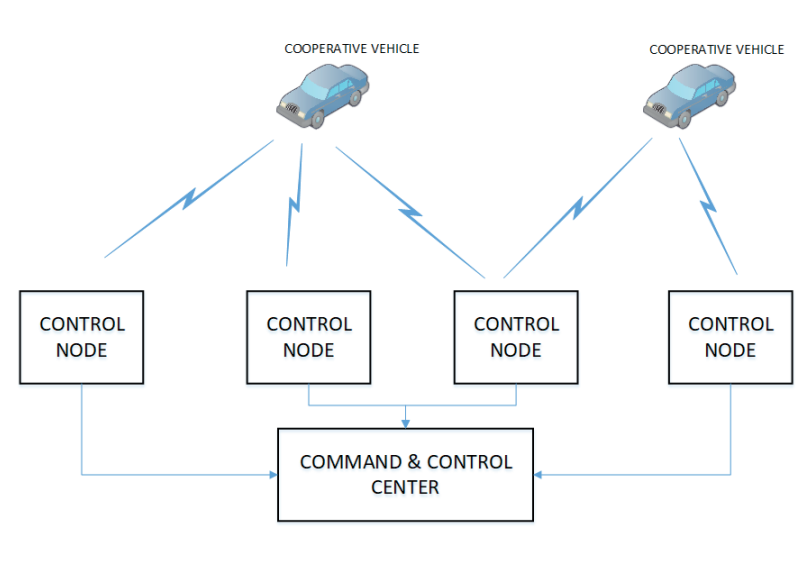

Fig. 8. Cooperative vehicles scenario

The difference is that in this case control nodes receive information from moving vehicles. Information about cooperative vehicle's position and radar orientation is obtained from GPS receiver, IMU sensor and digital magnetic compass installed in the vehicle.

Taking into account huge amount of raw data provided by the radar, it is clear that raw data from the radar installed on the moving cooperative vehicle cannot be transferred to control node. Limitations of radio communication network between cooperative vehicle and control node defines the amount of data that can be transferred between them. Unlike static scenario where communication network is sufficient for throughputs in range of 150-600 Mbps, in dynamic scenario cooperative vehicles can only send information about the positions of detected objects. In this case, radio communication network between cooperative vehicle and control node can either be mobile network (3G or LTE) or vehicular ad-hoc network (VANET).

\section{CONCLUSION}

Traffic monitoring in smart city is usually performed using cameras, which implies huge requirements 
in communication bandwidth. Depending on video quality, required communication bandwidth for a single camera is usually in range from about $1 \mathrm{Mbps}$ to $10 \mathrm{Mbps}$. This paper analyzed the possibility to replace these cameras with EBR radars and its impact on requirements for communication and power network for them. We have analyzed two scenarios - static scenario with fixed position of radars and dynamic scenario with radars installed in cooperative vehicles.

The analysis of urban use case with fixed position of radars showed that fusion of raw data taken from radars with overlapping radar coverage zones is performed in control nodes. Typically, one control node processes raw signals from three adjacent radars with overlapping coverage zones. Taking into account that raw image throughput from radar to control node is $150-600 \mathrm{Mbps}$ and that the radars are intended to be installed on utility poles used for city lighting, fiber-optic communication is the first choice for communication network.

The analysis of dynamic scenario with radars installed in cooperative vehicles showed that available radio technologies do not allow the transmission of huge amounts of raw data between cooperative vehicle and control node. Cooperative vehicle can only send information about the positions of detected objects.

In terms of power requirements, since power consumption is less then $20 \mathrm{~W}$ per radar and in case of radar installation on utility poles used for city lighting, first choice would be city grid. As a backup or alternative, solar panels could provide sufficient power supply.

\section{REFERENCES}

[1] N.Q. Dao, Q. Le-Dang, R. Morawski, A-T Dang, T. le-Ngoc, "Management of Video Surveillance for Smart Cities", M. Maheswaran E. Badidi - editors, Handbook of Smart Cities - Software Serevices and Cyber Infrastructure, Springer Nature Switcherland, AG, 2018

[2] System Assessment and Validation for Emergency Responders (SAVER), CCTV Technology Handbook, U.S. Department of Homeland Security, Science and Technology Directorate, July 2013.

[3] K. Paulsen, Moving Media Storage Technologies - Applications e Workflows for Video and Media Server Platforms, Elsevier, 2011.

[4] K. J. Ma, R. Batros, S. Bahtia, "A Survey of Schemes for Internet-based Video Delivery", Journal of Network and Computer Applications, Science Direct, Elsevier, 2011.
[5] L. Chaisorn, Y. Wong, "Video Analytics for Surveillance Camera Networks", 19th IEEE International Conference on Networks (ICON), Singapore, 11-13 Dec. 2013.

[6] G. A. Mutiara, A. A G. Agung, R. Handayani, "Sensor Comparation for Smart Parking System", 1st International Conference on Wireless and Telematics (ICWT), Manado, Indonesia, 17-18 Nov. 2015.

[7] A. Bazzi, C. Kärnfelt, A. Péden, T. Chonavel, P. Galaup, F. Bodereau, "Estimation techniques and simulation platforms for $77 \mathrm{GHz}$ FMCW ACC radars", Eur. Phys. J. Appl. Phys., Volume 57, Number 1, January 2012

[8] K.Geary, J. Colburn, A. Bekaryan, S. Zeng, B. Litkouhi ; M. Murad, "Automotive radar target characterization from 22 to $29 \mathrm{GHz}$ and 76 to $81 \mathrm{GHz}$,, 2013 IEEE Radar Conference (RadarCon13), Ottawa, ON, Canada, 29 April-3 May 2013

[9] N. Yamada, Y. Tanaka, K. Nishikawa, "Radar cross section for pedestrian in 76GHz band", 2005 European Microwave Conference, Paris, France, 4-6 Oct 2005.

[10] J.Sánchez-Oro, D.Fernández-López, R.Cabido, A.S.Montemayor, J.J.Pantrigo, "Radar-based roadtraffic monitoring in urban environments", Elsevier Digital Signal Processing, Vol. 23, Issue 1, January 2013.

[11] ITU-R Recommendation M.2057-1, "Systems characteristics of automotive radars operating in the frequency band $76-81 \mathrm{GHz}$ for intelligent transport systems applications", International Telecommunication Union, 2018.

[12] ITU-R Recommendation M.452-2, "Millimetre wave vehicular collision avoidance radars and radiocommunication systems for intelligent transport system applications", International Telecommunication Union, 2012.

[13] S. Narnakaje, "TI's smart sensors ideal for automated driving applications", SPYY009, Texas Instruments, 2017.

[14] M.Ferri, G.Galati, F.Marti, P.F. Pellegrini, E. Piazza, "Design and Field Evaluation of Millimetre-wave surface Movement Radar", Radar 97, 14-16 October 1997.

[15] Gaspare Galati ; Emilio G. Piracci ; Mauro Ferri, "High resolution, millimeter-wave radar applications to airport safety", 2016 8th International Conference on Ultrawideband and Ultrashort Impulse Signals (UWBUSIS), Odessa, Ukraine,5-11 Sept. 2016

[16] ELVA-1 76GHz Fault Object Detection (FOD) radar, datasheet, ELVA-1, available on-line: http://www. elva-1.com/, accessed on 3-Apr-2019.

[17] Meril I. Skolnik, Radar Handbook, third edition, McGraw-Hill, 2008. 